\title{
EFEITO DA ADIÇÃO DE TRANSGLUTAMINASE E GELATINA NA VISCOSIDADE DE BEBIDAS LÁCTEAS FERMENTADAS FABRICADAS COM SORO DE QUEIJO DE COALHO
}

\section{Effect of transglutaminase and gelatin on the viscosity of fermented dairy beverages made with "Coalho" type cheese whey}

\author{
Gisela de Magalhães Machado Moreiral, Renata Golin Bueno Costa , \\ Junio César Jacinto de Paula ${ }^{1}$, Denise Sobral ${ }^{1}$, Verônica Paula Batista ${ }^{2}$, Suellen Serafim Telles ${ }^{1}$
}

\section{RESUMO}

A transglutaminase é uma enzima utilizada na indústria de alimentos com o objetivo de produzir moléculas com alto peso molecular pela ligação entre proteínas, agregando características ao produto final, como aumento de viscosidade. Este trabalho teve como objetivo comparar a viscosidade de bebidas lácteas fermentadas sem nenhum aditivo com a viscosidade de bebidas lácteas adicionadas de transglutaminase, estabilizante (gelatina), e ambos os ingredientes. Foram fabricadas bebidas lácteas fermentadas com $50 \%$ de soro de queijo de coalho em 4 tratamentos, essas bebidas foram estocadas por 28 dias a $7{ }^{\circ} \mathrm{C}$ e sua viscosidade foi analisada em duplicata semanalmente durante este período. O experimento foi realizado em três repetições e os dados foram analisados pelos testes de Kruskal-Wallis e Tukey. Observou-se que a transglutaminase adicionada de glutationa teve efeito semelhante à gelatina na viscosidade das bebidas lácteas produzidas nas condições aplicadas, superando o tratamento controle (sem adição de enzima e estabilizante), o que torna essa uma alternativa tecnológica interessante para esse tipo de produto, do ponto de vista de incremento na viscosidade. Não houve efeito significativo de tempo sobre a viscosidade das amostras.

Palavras-chave: propriedade reológica; estabilizante; ligação cruzada.

1 Empresa de Pesquisa Agropecuária de Minas Gerais, Instituto de Laticínios Cândido Tostes (EPAMIG/ILCT), Rua Tenente Luiz de Freitas, 116, 36045-560, Juiz de Fora, MG, Brasil. E-mail: giselammachado@epamig.br

* Autor para correspondência.

Recebido / Received: 14/03/2014

Aprovado / Approved: 27/08/2014 


\begin{abstract}
Transglutaminase is an enzyme used in the food industry with the objective to produce molecules with high molecular weight by linking proteins, adding characteristics to the final product, such as increased viscosity. This study aimed to compare the viscosity of fermented dairy beverages without additives with the viscosity of dairy beverages added with transglutaminase, stabilizer (gelatin), and both ingredients. Fermented dairy beverages were made with $50 \%$ of "Coalho" type cheese whey in 4 treatments, these drinks were stored for 28 days at $7{ }^{\circ} \mathrm{C}$ and its viscosity was analyzed in duplicate weekly during this period. The experiment was performed in three replicates and the data were analyzed by Kruskal-Wallis and Tukey tests. It was observed that transglutaminase with glutathione had a similar effect to gelatin in the viscosity of dairy beverages produced under the conditions applied, exceeding the control treatment (without addition of enzyme and stabilizer), which makes this an interesting alternative technology for this type of product, with respect to viscosity increment. There was no significant effect of time on the viscosity of the samples.
\end{abstract}

Keywords: rheological property; stabilizer; cross-linking.

\section{INTRODUÇÃO}

O uso de aditivos na indústria de alimentos tem o objetivo de acrescentar propriedades funcionais e sensoriais ao produto final, melhorando sua qualidade e apresentação ao consumidor. A tendência do consumidor contemporâneo de procurar alimentos saudáveis para sua alimentação leva à necessidade de adequação da indústria na busca de novos aditivos que agreguem propriedades relevantes ao produto. O uso de enzimas produzidas por microrganismos tem relevada importância neste contexto, uma vez que suas características de especificidade são interessantes e sua atividade pode levar a uma modificação controlada e desejável nas características do alimento, até mesmo incorporando facilidade ao processo de produção e funcionalidade ao produto final. A modificação de proteínas por meio da utilização de enzimas é um método promissor para melhorar suas propriedades funcionais e seu valor nutritivo nos diversos alimentos (FARIÑA et al., 2004).

A modificação de proteínas por enzimas como a transglutaminase recentemente tem se tornado de grande interesse para os cientistas da área de alimentos (ÖZRENK, 2006). A transglutaminase - TG (EC 2.3.2.13) é uma enzima obtida a partir de fungos que apresenta um largo espectro de aplicação na indústria de alimentos, por tornar possível a união de proteínas que normalmente não possuem condições de ligação (FARIÑA et al., 2004). A TG catalisa uma reação de transferência de grupos acil entre o grupo carboxi-amida da ligação peptídica nos resíduos de glutamina (doadores de grupo acil) e uma variedade de aminas primárias (receptoras do grupo acil), incluindo o grupo amino de resíduos de lisina em certas proteínas. Na ausência de substratos amina, TG catalisa a desaminação dos resíduos de glutamina nos quais moléculas de água são utilizadas como receptoras de grupo acil. Assim, TG pode modificar proteínas por meio de incorporação de aminas, ligações cruzadas (crosslinking) e desamidação (MOTOKI; SEGURO, 1998). Estudos sugerem que o dipeptídio formado não afeta nutricionalmente a absorção de lisina na dieta (JAROS et al., 2006). 
Em linhas gerais, proteínas lácteas tem se mostrado bons substratos para as reações catalisadas pela transglutaminase (BÖNISCH et al., 2007a). Individualmente, tanto as caseínas quanto as soroproteínas são bons substratos para a transglutaminase, mas em um sistema composto, como no leite, as caseínas fazem ligação cruzada preferencialmente em relação às soroproteínas nativas (O’SULLIVAN et al., 2002). A fração caseínica é um substrato favorável para ação da transglutaminase principalmente devido à sua estrutura altamente acessível e à sua cadeia aberta e flexível (ILIČIĆ et al., 2013). Já a $\beta$-lactoglobulina nativa não é um substrato ativo da transglutaminase, uma vez que as frações de glutamina e lisina envolvidas na reação estão inacessíveis dentro da estrutura protéica enovelada, porém pode ser tornar ativa após uma desnaturação térmica. A $\alpha$-lactoalbumina pode sofrer ligação cruzada pela enzima diretamente (WANG et al., 2013).

A glutationa é uma substância que tem sido utilizada para aprimorar a atuação da transglutaminase sobre as proteínas do leite. Essa substância pode ser adicionada pura ou em uma preparação contendo a enzima de interesse e extrato de levedura como fonte de glutationa. A ligação cruzada promovida pela transglutaminase é melhorada devido ao fato da glutationa possivelmente interferir na interação entre a enzima e seu inibidor presente naturalmente no soro do leite. A glutationa tem efeito similar ao tratamento térmico no melhoramento da atividade de transglutaminase e, portanto seu uso pode eliminar esta etapa da produção de leites fermentados adicionados de transglutaminase (desde que mantida a pasteurização) (BÖNISCH et al., 2007a).

A adição da enzima transglutaminase em leite incorre em mudanças nas suas propriedades físico-químicas. $\mathrm{O}$ tratamento do leite pré-aquecido com transglutaminase e com teor reduzido de gordura resulta em um gel mais firme e sinérese reduzida em leites fermentados (ILIČIĆ et al., 2013). Estudo feito por O'Sullivan et al. (2002) aponta as seguintes alterações em leite devido à ação de transglutaminase: aumento da estabilidade térmica do leite, principalmente em leite pré-aquecido; aumento do tempo por coagulação pela quimosina; redução da extensão da dissociação das micelas de caseína pelos seguintes tratamentos dissociantes: adição de uréia, adição de citrato de sódio, remoção de fosfato de cálcio coloidal por acidificação/diálise; aumento na resistência das micelas à diminuição de tamanho devido a altas pressões; e aumento na resistência da hidrólise de $\beta$-caseína por plasmina.

De acordo com a Resolução $\mathrm{n}^{\circ} 5$ do Ministério da Agricultura e do Abastecimento, de 13 de novembro de 2000, que oficializa os padrões de identidade e qualidade de leites fermentados, tem-se que leites fermentados são produtos resultantes da fermentação do leite pasteurizado ou esterilizado por fermentos láticos próprios, sendo que estes fermentos devem ser viáveis, ativos e abundantes no produto final durante seu prazo de validade (BRASIL, 2000). Bebida láctea, conforme Instrução Normativa $\mathrm{n}^{\circ} 16$ do Ministério da Agricultura e do Abastecimento, de 23 de agosto de 2005, é o produto obtido a partir de leite ou leite reconstituído e/ou derivados do leite, reconstituído ou não, fermentado ou não, com ou sem adição de outros ingredientes, onde a base láctea represente pelo menos $51 \%$ em massa do total de ingredientes do produto (BRASIL, 2005).

O queijo de coalho é um queijo tradicionalmente produzido na região nordeste onde é feito artesanalmente e o seu consumo está incorporado à cultura desta região. (MUNCK, 2004). O queijo de coalho está gradualmente ganhando espaço também nas outras regiões brasileiras, especialmente nas regiões costeiras, onde normalmente é consumido assado na brasa. Por ser um queijo produzido comumente de forma artesanal por mão de obra familiar, o uso do soro oriundo da sua fabricação em bebidas lácteas é uma 
alternativa que colabora tanto no sentido de redução de resíduos quanto para melhorar a renda dos produtores.

Este trabalho teve como objetivo comparar a viscosidade de bebidas lácteas fermentadas sem nenhum aditivo com a viscosidade de bebidas lácteas fermentadas adicionadas de transglutaminase, estabilizante (gelatina), e ambos os ingredientes.

\section{MATERIAL E MÉTODOS}

Os testes foram realizados no Laboratório de Pesquisa e Desenvolvimento de Produtos do Instituto de Laticínios Cândido Tostes (ILCT) da EPAMIG, em Juiz de Fora, MG.

As bebidas lácteas foram fabricadas em quatro tratamentos, a saber:

- Controle (sem enzima e sem estabilizante);

- TG (com adição de transglutaminase);

- GEL (com o estabilizante gelatina);

- TG/GEL (com enzima e estabilizante).

A primeira etapa consistiu em fabricar queijo de coalho conforme descrito em Sobral et al. (2007) para retirada do soro que foi tratado termicamente (aquecimento até $65^{\circ} \mathrm{C}$ ) para inativação das enzimas do coalho. A bebida foi feita em seguida com $50 \%$ deste soro termizado e $50 \%$ de leite integral pasteurizado em quatro cubas, sendo uma para cada tratamento. Um alto teor de soro foi utilizado para maximizar o aproveitamento deste subproduto na fabricação de bebida láctea, respeitando a legislação pertinente já citada. À mistura de leite e soro foram adicionados açúcar (na concentração final de $10 \%$ ) e gelatina em pó (este último somente às cubas dos tratamentos GEL e TG/GEL na concentração de $0,3 \%$ ). A temperatura foi elevada em todas as cubas até $85{ }^{\circ} \mathrm{C}$ e essa temperatura foi mantida por 15 minutos para desnaturar o inativador de TG natural presente no soro e no leite (FARIA, 2010). A transglutaminase $(0,04 \%$ da preparação industrial All Taste ${ }^{\circledR}$ contendo glutationa e com atividade enzimática declarada de 90U/g - concentração final estimada no produto de $1 \mathrm{U} / \mathrm{g}$ de proteína) foi adicionada às cubas dos tratamentos TG e TG/GEL. Após incubar as bebidas a $50{ }^{\circ} \mathrm{C}$ por $2 \mathrm{~h}$ para ação da enzima foi realizado tratamento térmico $95{ }^{\circ} \mathrm{C}$ por 2 minutos para inativar a TG seguido de resfriamento até $38^{\circ} \mathrm{C}$. O fermento probiótico termofílico ABT4 $\mathrm{Chr}$ Hansen $^{\circledR}$ (L. acidophilus, Bifidobacterium e S. thermophilus) foi adicionado na proporção recomendada pelo fabricante (50U para cada 500 litros de bebida) e a fermentação ocorreu até o dia seguinte, quando o $\mathrm{pH}$ chegou a 4,6. Essa cultura foi utilizada para agregar valor ao produto final, sem prejuízo do processo de fermentação. Para finalização da bebida, a coalhada foi quebrada e homogeneizada manualmente e o envase foi feito em frascos plásticos inócuos e mantidos sob refrigeração em câmaras de incubação de temperatura controlada a $7^{\circ} \mathrm{C}$ por 28 dias. $\mathrm{O}$ experimento todo foi realizado em três repetições.

A viscosidade dessas bebidas foi avaliada em quatro tempos: 7, 14, 21 e 28 dias após a data da fabricação. Os dados foram avaliados em temperatura de armazenamento por viscosímetro Brooksfield ${ }^{\circledR}$ RVT utilizando haste 1 e rotação de 100 RPM por 2 minutos. Os resultados foram analisados pelo método de Kruskal-Wallis e Tukey por programa estatístico apropriado Mini Tab $^{\circledR}$ (MINITAB STATISTICAL SOFTWARE, 2003).

\section{RESULTADOS E DISCUSSÃO}

Os dados apresentados na Tabela 1 são a média das repetições realizadas com seus respectivos desvios padrão. Esses dados de viscosidade não apresentaram comportamento Normal pelo teste de Anderson-Darling $(\mathrm{p}<0,05)$ e, portanto, foi realizada a análise não paramétrica - teste de Kruskal-Wallis, que mostrou haver diferença significativa de tratamentos $(\mathrm{p} \geq 0,05)$ para os valores de 
viscosidade. Não houve efeito significativo de tempo $(\mathrm{p}<0,05)$ e, portanto o tempo de estocagem não alterou significativamente a viscosidade das amostras.

Observou-se que os tratamentos GEL e TG/GEL superaram o tratamento CONTROLE com relação à viscosidade e os tratamentos GEL, TG e TG/GEL não apresentaram diferenças significativas com relação à viscosidade. Esse fato pode ser explicado pela semelhança dos efeitos da adição dessas duas substâncias nas bebidas lácteas, embora o mecanismo de atuação seja bem diferente. $\mathrm{O}$ aumento de viscosidade causado pela gelatina se dá pelas longas cadeias moleculares flexíveis entre as ligações cruzadas da molécula de colágeno (transformada em gelatina), que fazem com que o gel seja muito extensível. Além disso, este gel é predominantemente elástico devido ao caráter permanente destas ligações cruzadas, ao menos em baixas temperaturas, produzindo assim soluções aquosas altamente viscosas (WALSTRA, 1996). Já a transglutaminase atua unindo frações proteicas, o que potencialmente leva ao aumento na viscosidade dos sistemas em que estão presentes, uma vez que ocorre a formação de moléculas com maior peso molecular (FARIA, 2010). A interação entre transglutaminase e gelatina também deve ser considerada, porém seu efeito mais relevante é na estabilidade do gel, que se torna mais estável em altas temperaturas (KURAISHI et al., 2001).

Os desvios padrão das médias de viscosidade apresentadas para os diferentes tratamentos, embora elevados, não ultrapassam $35 \%$ do valor de viscosidade, como observado para o tratamento GEL. Para os demais tratamentos foi encontrada uma variabilidade menor que $30 \%$ nas médias das medidas de viscosidade, tendo em vista os coeficientes de variação para cada medida. Isso evidencia uma variabilidade admissível para os dados apresentados, considerando as diferenças naturais e inerentes entre as repetições que, por mais que minimizadas, ainda estão presentes, como por exemplo, a composição inicial do leite integral e do soro e a atuação dos microrganismos sobre esses componentes ao longo do tempo de fermentação.

Os resultados encontrados neste trabalho estão em concordância com valores

Tabela 1 - Médias das viscosidades das bebidas lácteas fermentadas em centipoise (cP), com seus respectivos desvios padrão (DP) e coeficientes de variação (CV)

\begin{tabular}{ccccccccc}
\hline Tratamentos* & \multicolumn{2}{c}{ Controle } & \multicolumn{2}{c}{ TG } & \multicolumn{2}{c}{ GEL } & \multicolumn{2}{c}{ TG/GEL } \\
\hline Tempo & $\begin{array}{c}\text { Média } \pm \\
\text { DP }\end{array}$ & CV & $\begin{array}{c}\text { Média } \pm \\
\text { DP }\end{array}$ & CV & $\begin{array}{c}\text { Média } \pm \\
\text { DP }\end{array}$ & CV & $\begin{array}{c}\text { Média } \pm \\
\text { DP }\end{array}$ & CV \\
\hline 7 dias & $137,3 \pm 41,6$ & $30 \%$ & $158,0 \pm 40,1$ & $25 \%$ & $216,7 \pm 78,0$ & $36 \%$ & $174,0 \pm 28,8$ & $17 \%$ \\
14 dias & $138,7 \pm 37,9$ & $27 \%$ & $152,7 \pm 31,0$ & $20 \%$ & $233,3 \pm 107,4$ & $46 \%$ & $201,3 \pm 52,6$ & $26 \%$ \\
21 dias & $140,0 \pm 72,6$ & $52 \%$ & $168,7 \pm 68,4$ & $41 \%$ & $246,7 \pm 120,2$ & $49 \%$ & $205,3 \pm 75,3$ & $37 \%$ \\
28 dias & $133,3 \pm 21,2$ & $16 \%$ & $168,7 \pm 37,1$ & $22 \%$ & $271,3 \pm 77,6$ & $29 \%$ & $244,7 \pm 32,4$ & $13 \%$ \\
Média** $^{*}$ & $137,3 \pm 40,3^{\mathrm{b}}$ & $29 \%$ & $162,0 \pm 40,3^{\text {ab }}$ & $25 \%$ & $242,0 \pm 85,8^{\text {a }}$ & $35 \%$ & $206,3 \pm 50,7^{\text {a }}$ & $25 \%$ \\
\hline
\end{tabular}

*Tratamento Controle: bebida láctea composta de leite integral (50\%), soro de queijo de coalho (50\%) e açúcar (10\% sobre a base láctea). TG: mesma formulação do tratamento controle adicionada de $1 \mathrm{U} / \mathrm{g}$ de proteína. GEL: mesma formulação do tratamento controle adicionada de gelatina em pó na concentração final de $0,3 \%$ $\mathrm{m} / \mathrm{v}$. TG/GEL: mesma formulação do tratamento controle adicionada de $1 \mathrm{U} / \mathrm{g}$ de proteína e gelatina em pó na concentração final de $0,3 \% \mathrm{~m} / \mathrm{v}$.

**Médias seguidas de letras iguais indicam valores semelhantes pelo teste de Tukey ao nível de 5\% de probabilidade. 
encontrados na literatura. Costa et al. (2013) avaliaram bebidas lácteas feitas com $50 \%$ de soro de queijo e $50 \%$ de leite adicionadas de estabilizantes. A bebida com $1 \%$ de gelatina apresentou viscosidade de $1.142 \mathrm{cP}$ medida a 30 RPM e 806,67 cP a 60 RPM. A mesma bebida fabricada com metade da dose de gelatina $(0,5 \%)$ apresentou $537,3 \mathrm{cP}$ e 402,0 cP para 30 RPM e 60 RPM, respectivamente.

Em estudo realizado por pesquisadores sérvios, leite fermentado produzido com cultura starter probiótica contendo $0,02 \%$ de TG ativada tem $39 \%$ mais firmeza e $48 \%$ mais consistência que o mesmo produto feito sem ação da TG, que pode ser uma conseqüência da ação enzimática formando pontes proteicas e uma matriz mais forte (ILIČIĆ et al., 2013). Maiores viscosidade e polimerização proteica foram encontradas em iogurtes em que a coalhada foi quebrada para o envase, assim como realizado neste trabalho, em relação aos iogurtes controle (sem adição de enzima). Para o produto com enzima uma redução de $1,2 \%$ no conteúdo proteico do produto pode ser realizada obtendo-se a viscosidade desejada de 0,07Pa.s (70cP) (BÖNISCH et al., 2007b).

Faria (2010) utilizou leite em pó e soro de leite em pó (equivalente de $40 \%$ de soro líquido) na fabricação de bebidas lácteas com transglutaminase adicionada de glutationa em várias concentrações e temperaturas de incubação. A bebida contendo $0,034 \%$ da preparação industrial enzimática (1,6 U/g de proteína) e $40{ }^{\circ} \mathrm{C}$ de incubação chegou à viscosidade de $850 \mathrm{cP}$ aos 18 dias de estocagem, superando a viscosidade da amostra controle em $81 \%$. Gauche e colaboradores (2009) produziram bebidas lácteas com leite e $20 \%$ e $30 \%$ de soro seguidos de tratamento térmico. A viscosidade aparente das amostras foram maiores quando foram submetidas ao tratamento enzimático com transglutaminase a $0,5 \mathrm{U} / \mathrm{g}$ de proteína, adicionada antes do processo fermentativo. Dessa forma, a transglutaminase atuou sobre a matriz proteica das amostras produzindo um aumento na força do gel (GAUCHE et al., 2009).

\section{CONCLUSÕES}

As bebidas lácteas fermentadas fabricadas com soro de queijo de coalho não sofreram modificação da viscosidade com o tempo de estocagem refrigerada, indicando que o produto conservará essa propriedade durante seu período de validade. Observou-se que a adição de gelatina e transglutaminase causaram um aumento na viscosidade das bebidas em relação ao tratamento controle e que não houve diferença entre os tratamentos utilizando um dos aditivos ou ambos, nas condições testadas. Dessa forma, a transglutaminase é uma alternativa tecnológica interessante para esse tipo de produto, do ponto de vista de incremento na viscosidade.

\section{AGRADECIMENTOS}

À Fundação de Amparo à Pesquisa do Estado de Minas Gerais (Fapemig) pelo financiamento da pesquisa (APQ-03724-10) e pelas bolsas concedidas.

\section{REFERÊNCIAS}

BRASIL. Ministério de Estado da Agricultura, Pecuária e Abastecimento. Instrução Normativa n. 16, de 23 de agosto de 2005. Aprova o Regulamento Técnico de Identidade e Qualidade de Bebida Láctea. Diário Oficial da República Federativa do Brasil, Brasília, 24 ago. 2005. Seção I, p. 7.

BRASIL. Ministério de Estado da Agricultura, Pecuária e Abastecimento. Resolução n. 5, de 13 de novembro de 2000. Oficializa os padrões de identidade e qualidade de leites fermentados. Diário Oficial da República Federativa do Brasil, Brasília, 27 nov. 2000. Seção I, p. 9-12. 
BÖNISCH, M. P.; LAUBER, S.; KULOZIK, $\mathrm{U}$. Improvement of enzymatic cross-linking of casein micelles with transglutaminase by glutathione addition. International Dairy Journal, v. 17, n. 1, p. 3- 11, 2007a.

BÖNISCH, M. P. et al. Yoghurt gel formation by means of enzymatic protein crosslinking during microbial fermentation. Food Hydrocolloids. v. 21, n. 4, p. 585-595. 2007 b.

COSTA, A. V. S. et al. Desenvolvimento e caracterização físico-química, microbiológica e sensorial de bebida láctea fermentada elaborada com diferentes estabilizantes/ espessantes. Semina: Ciências Agrárias, v. 34, n. 1, p. 209-226, 2013.

FARIA, D. S. Estudo dos efeitos de aplicação de transglutaminase em bebida láctea fermentada com alto conteúdo de soro. 2010. 118f. Dissertação (Mestrado em Engenharia de processos Químicos e Bioquímicos) - Centro Universitário do Instituto Mauá de Tecnologia, São Caetano do Sul, 2010.

FARIÑA, L. O. et al. Estudos das características físico-químicas reológicas e sensoriais do requeijão cremoso produzido com adição de transglutaminase. Revista do Instituto de Laticínios Cândido Tostes, v. 59, n. 339, p. 163/166, 2004.

GAUCHE, C. et al. Physical properties of yoghurt manufactured with milk whey and transglutaminase. Food Science and Technology. v. 42, n. 1, p. 239-243, 2009.

ILIČIĆ, M. D. et al. The effect of transglutaminase on rheology and texture of fermented milk products. Journal of Texture Studies, v. 44, n. 2, p. 160-168, 2013.

JAROS, D.; PARTSCHEFELD, C.; HENLE, T.; ROHM, H. Transglutaminase in dairy products: chemistry, physics, applications.
Journal of Texture Studies. v. 37, n. 2, p.113-155, 2006.

KURAISHI, C.; YAMAZAKI, K.; SUSA, Y. Transglutaminase: its utilization in the food industry. Food Reviews International, v. 17, n. 2, p. 221-246, 2001.

MINITAB STATISTICAL SOFTWARE. Meet MINITAB versão 14. [S. 1.], 2003.

MUNCK, A. V. Queijo de coalho: princípios básicos da fabricação. Revista do Instituto de Laticínios Cândido Tostes, v. 59, n. 339, p. 13-15, 2004

MOTOKI, M.; SEGURO, K. Transglutaminase and its use for food processing. Trends in Food Science \& Technology, v. 9, n. 5, p. 204-210, 1998.

SOBRAL, D.; PAULA, J. C. J. de; SILVA, P. H. F. da. Queijo de coalho: características e tecnologia. Informe Agropecuário. Agroindústria: leite e derivados, v. 28, n. 238, p. 57-62, 2007.

O'SULLIVAN, M. M.; KELLY, A. L.; FOX, P. F. Influence of transglutaminase treatment on some physico-chemical properties of milk. Journal of Dairy Research, v. 69, n. 3, p. 433-442, 2002.

ÖZRENK, E. The use of transglutaminase in dairy products. International Journal of Dairy Technology, v. 59, n. 1, p. 1-7, 2006.

WALSTRA, P. Dispersed Systems: Basic Considerations. In: FENNEMA, O. (Ed.).

Food Chemistry. 3rd Edition. New York: Marcel Dekker, 1996. p. 95-155.

WANG, W.; ZHONG, Q.; HU, Z. Nanoscale Understanding of Thermal Aggregation of Whey Protein Pretreated by Transglutaminase. Journal of Agricultural and Food Chemistry, v. 61, n. 2, p. 435-446, 2013. 